\title{
Five-year results of cervical disc prostheses in the SWISSspine registry
}

\author{
Emin Aghayev $\cdot$ Christian Bärlocher • Friedrich Sgier • Mustafa Hasdemir • Klaus F. Steinsiepe • \\ Frank Wernli • François Porchet · Oliver Hausmann • Aymen Ramadan · Gianluca Maestretti • \\ Uwe Ebeling $\cdot$ Michal Neukamp $\cdot$ Christoph Röder
}

Received: 10 October 2012/Revised: 18 March 2013/Accepted: 1 April 2013/Published online: 13 April 2013

(C) Springer-Verlag Berlin Heidelberg 2013

\begin{abstract}
Background The Swiss Federal Office of Public Health demanded a nationwide HTA-registry for cervical total disc arthroplasty (TDA), to decide about its reimbursement. The goal of the SWISSspine registry is to generate evidence about the safety and efficiency of cervical TDA. Materials and methods Three hundred thirty-two cases treated between 3.2005 and 6.2006 who were eligible for 5 years follow-ups were included in the study. Follow-up rates for 3-6 months, 1, 2 and 5 years were 84.6, 74.4, 50.6 and $64.8 \%$, respectively. Outcome measures were neck and arm pain, medication, quality of life, intraoperative and postoperative complication and revision rates. In addition, segmental mobility, ossification, adjacent and distant segment degeneration were analyzed at the 5-year follow-up. Results There was significant, clinically relevant and lasting reduction of neck (preop/postop 60/21 VAS points) and arm pain (preop/postop VAS 67/17) and a consequently decreased analgesics consumption and quality of life improvement (preop/postop 0.39/0.82 EQ-5D points)
\end{abstract}

On behalf of the SWISSspine Registry Group.

\section{E. Aghayev $(\varangle) \cdot$ M. Neukamp · C. Röder}

Institute for Evaluative Research in Orthopedic Surgery,

University of Bern, Stauffacherstrasse 78, 3014 Bern,

Switzerland

e-mail: emin.aghayev@memcenter.unibe.ch

C. Bärlocher

Stephanshorn Hospital, Brauerstrasse 95, 9016 St. Gallen, Switzerland

F. Sgier · O. Hausmann

St. Anna Clinic, St. Anna-Strasse 32, 6006 Luzern, Switzerland

M. Hasdemir · F. Wernli

Salem Hospital, Schänzlistrasse 39, 3000 Bern, Switzerland until the 5-year follow-up. The rates for intraoperative and early postoperative complications were 0.6 and $7.2 \%$, respectively. In $0.6 \%$ an early and in $3.9 \%$ a late revision surgery was performed. At the 5-year follow-up, the average range of motion of the mobile segments (88.2\%) was $10.2^{\circ}$. In $40.7 \%$ of the patients osteophytes at least potentially affecting range of motion were seen.

Conclusions Cervical TDA appeared as safe and efficient in long-term pain alleviation, consequent reduction of pain killer consumption and in improvement of quality of life. The improvement is stable over the 5 years postoperative period. The vast majority of treated segments remained mobile after 5 years, although $40.7 \%$ of patients showed osteophytes.

Keywords SWISSspine - TDA · Disc arthroplasty · Cervical disc prosthesis $\cdot$ Long-term follow-up

\section{Introduction}

The global market of cervical disc arthroplasties is constantly growing. Numerous implants are available and a

\author{
K. F. Steinsiepe · U. Ebeling \\ Lindenhof Hospital, Bremgartenstrasse 119, 3001 Bern, \\ Switzerland \\ F. Porchet \\ Schulthess Klinik, Lengghalde 2, 8008 Zurich, Switzerland \\ A. Ramadan \\ Clinique La Colline, Avenue de Beau-Séjour 6, 1206 Genèva, \\ Switzerland \\ G. Maestretti \\ Hôpital Cantonal de Fribourg, 1708 Fribourg, Switzerland
}


number of indications are covered. Total disc arthroplasty (TDA) may be the most innovative and exciting development in the history of spinal surgery [1]. It is a technique for the management of degenerative intervertebral disc disease in the younger adult population as an alternative to fusion. The primary goals of arthroplasty are to reduce or eliminate pain and restore and maintain normal segmental motion. A theoretical advantage of an arthroplasty compared with fusion is a reduction or elimination of adjacent segment disease requiring later surgical intervention. Artificial discs are quite attractive to the surgeon and to the "internet informed" patient who, both, desire pain relief with preservation of motion and with potentially decreased risk of adjacent segment disease [1]. The devices are also extremely attractive to the manufacturers and investors because they are anticipated to take over a large portion of the fusion market, representing billions of dollars of revenue [1]. The potential economic effect of spine arthroplasty in the United States is staggering with conservative figures approximating $\$ 2.18$ billion and $47.9 \%$ of the market share being captured by motion-sparing technology [2].

Currently, there is still inadequate evidence to promote extensive use of artificial discs for cervical spondylosis, despite promising short-term and intermediate clinical outcomes. However, there is also insufficient evidence to cease using them completely [3]. To date, several disc prosthesis types have been implanted in patients, but consistent data on their clinical results have been reported only for a few of them (Bryan disc and Prestige disc, Medtronic ${ }^{\circledR}$; Prodisc-C, Synthes ${ }^{\circledR}$; Moby-C, LDR-Spine ${ }^{\circledR}$; Kineflex, SpinalMotion ${ }^{\circledR}$ ) [4-8]. The long-term stability, durability and clinical efficiency of the prostheses are unknown for the majority of implants so far.

Due to increased use, reports on high complication rates, and uncertainty regarding treatment outcomes, a governmentally mandated national registry for disc arthroplasties and some other spine procedures was established in March 2005. Short-term outcomes of cervical disc arthroplasties from the so-called SWISSspine registry were already published [9]. The next step in the technology assessment was the collection of the 5-year follow-up results which are presented in the current article.

\section{Materials and methods}

\section{The SWISSspine registry}

The detailed setup of the registry was already reported [9]. The nationwide registry is ongoing since March 2005 and documents the following data: surgeon-based intervention and follow-up forms, patient based preoperative comorbidity form as well as pre- and postoperative North
American Spine Society outcome assessment instrument for the cervical spine (NASS) and EuroQoL-5D [9]. In addition an informed consent form is signed by each patient. The registry runs on the generic registry platform MEMdoc of the Institute for Evaluative Research in Orthopedic Surgery at the University of Bern [10]. Since the registry is a governmentally mandated quality and technology assessment project, no approval of the local ethics committee was needed.

\section{Sample characteristics}

Five-year follow-ups were initiated in 2011 and included 332 eligible patients, who were treated between March 1st 2005 and July 1st 2006. 55.4 \% were female. Both genders were on average 47 years old (SD 9 years; overall range 26-78 years). Bisegmental TDA was performed in $17.6 \%$ of patients. Figure 1 demonstrates proportions of different comorbidities at the time of surgery.

The following devices were implanted in the considered time period and included in the current report (in alphabetic order): Bryan and Prestige discs, Medtronic ${ }^{\circledR}$; Discocerv, Scient' ${ }^{\circledR}$; Moby-C disc, LDR Medical ${ }^{\circledR}$; ProDisc-C, Synthes ${ }^{\circledR}$.

The analyses focused on 3-6 month, 1, 2 and 5 year follow-ups. Surgeon-based follow-up rates for the given timepoints were 84.6, 74.4, 50.6 and $64.8 \%$, respectively. Despite trying to contact every patient for the 5-year follow-up, $27.3 \%$ of patients were not reached due to different reasons: patient moved away, surgeon moved away, patient unreachable, follow-up appointment could not be set up yet. Also, $7.5 \%$ of other patients were lost to followup due to unwillingness to participate, immobility or a reoperation on the same level with a spondylodesis (included in the revision rate).

\section{Outcome measures}

The following outcomes were assessed:

1. Neck and arm pain levels (VAS on NASS form).

2. Pain medication (based on pre- and postoperative surgeon forms: none, NSAIDs, weak opiates, strong opiates).

3. Quality of life (EuroQoL-5D, score ranging from -0.6 (worst possible QoL) to 1 (best possible QoL).

4. Complication and revision rates (based on pre- and postoperative surgeon forms and informal patient information).

5. Heterotopic ossification (HO) (only at the 5-year timepoint: (a) X-ray based surgeon assessment with an answer for ossification yes/no, (b) X-ray based assessment of an independent assessor using McAfee 
Fig. 1 Comorbidities (\%)

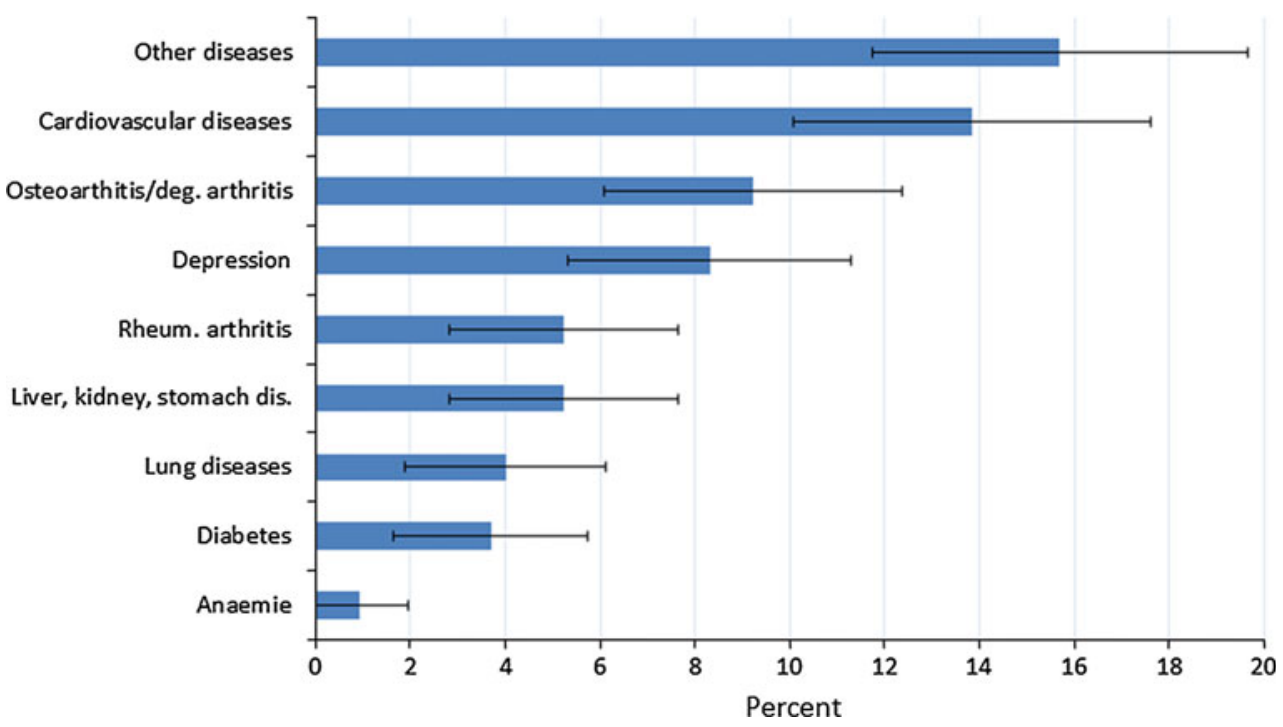

classification) [11]. Category 0—when no HO present; category I-when $\mathrm{HO}$ present in islands of bone within soft tissue but not influencing the range of motion of the vertebral motion segment; category II-when HO possibly affecting the vertebral range of motion and/or HO present between the two planes formed by the vertebral endplates; category III-when the range of motion of the vertebral endplates is blocked by the formation of $\mathrm{HO}$ and/or postoperative osteophytes on flexion-extension or lateral bending radiographs; and category IV-when HO is causing inadvertent arthrodesis bridging trabecular bone continuous between adjacent endplates and $<3^{\circ}$ of motion of lateral flexion-extension radiographs [11]. To compare the surgeon and independent assessors' ratings, McAfee categories 0 -II were grouped as no ossification and categories III and IV as ossification.

6. Segmental mobility (only at the 5-year timepoint: sagittal X-ray measurements in flexion and extension).

7. Adjacent segment degeneration (ASD). The involved surgeons indicated whether a progression of cranial, caudal or both adjacent segments as well as of cranial, caudal or both distant segments took place. Missing answers on this question were regarded as no progression of the degeneration.

\section{Statistical analysis}

Wilcoxon rank-sum test was used for comparisons between baseline and follow-up continuous variables such as pain on VAS. When comparing proportions, the Chi square test was used. $\alpha$ was set to 0.05 throughout the study. All statistical analyses were conducted using SAS 9.3 (SAS Institute, Inc., Cary, NC, USA).

\section{Results}

The average follow-up time for the 5-year follow-up was 5.4 years (95\% confidence interval 5.3-5.5 years; range $4.1-6.5$ years).

Pain levels and medication

There was a significant $(p<0.001)$ and long-lasting neck and arm pain relief from 60 and 67 points preoperative to 21 and 17 points postoperative at the fifth postoperative year. Thus, the average neck and arm pain reliefs until the fifth postoperative year were 41 and 52 points, respectively. The course of neck and arm pain is shown in Fig. 2.

The proportion of patients without medication increased from preoperative 2.8 to $82.1 \%$ at 5-years. Accordingly, the proportion of patients consuming NSAIDs, weak and strong opioids decreased from 85.6, 28.8 and 8.8 to $15,1.7$ and $2.3 \%$, respectively. Notably, the course of consumption reduction between the first and the fifth postoperative year was practically without change.

Quality of life

The improvement of quality of life was also significant and long-lasting. Preoperatively, the EuroQoL-5D score was 0.39 and at the 5-year follow-up it was 0.82 . The course of postoperative quality of life is shown in Fig. 3.

Segmental mobility and ossification

According to surgeon assessments, $90.2 \%$ of the segments were mobile and $24.1 \%$ of the segments had osteophytes. 

arm pain over 6.5 years with the $95 \%$ confidence intervals. All available follow-ups per patient considered
Fig. 2 The course of neck and

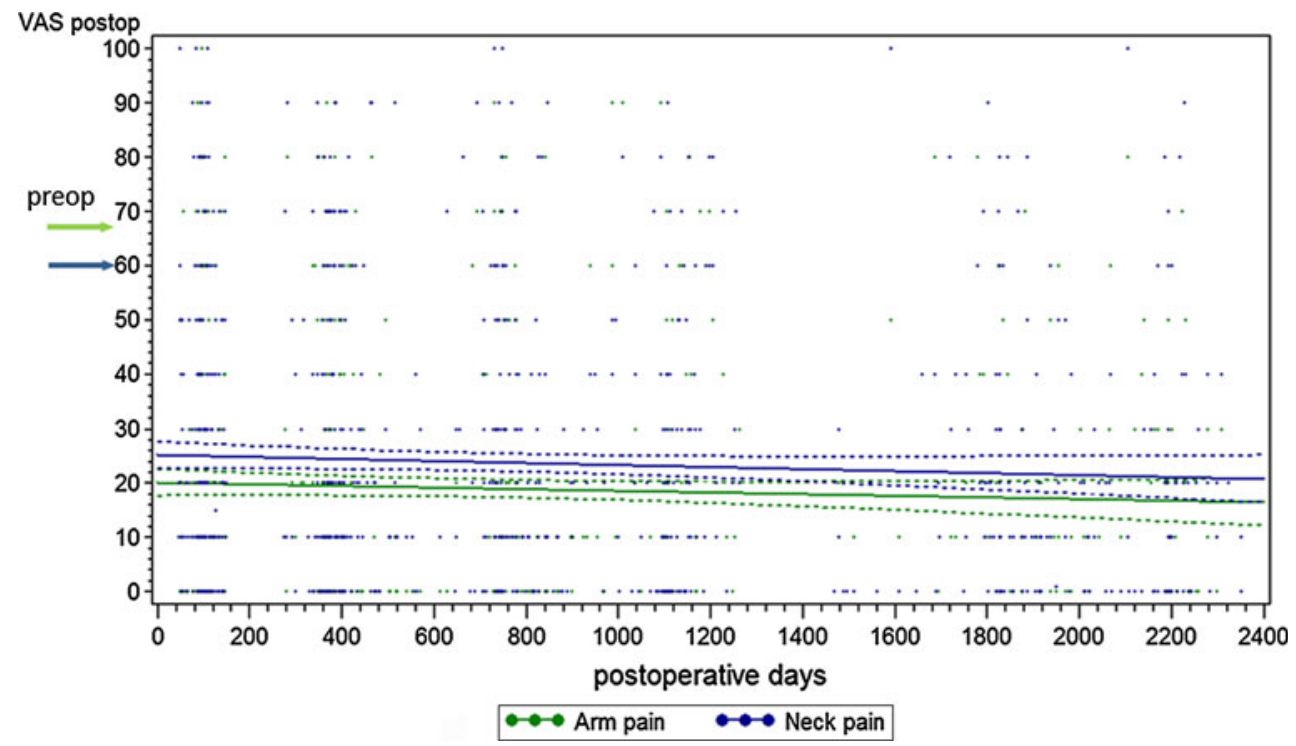

Fig. 3 The course of EQ-5D score based quality of life over 6.5 years with the $95 \%$ confidence intervals. All available follow-ups per patient considered

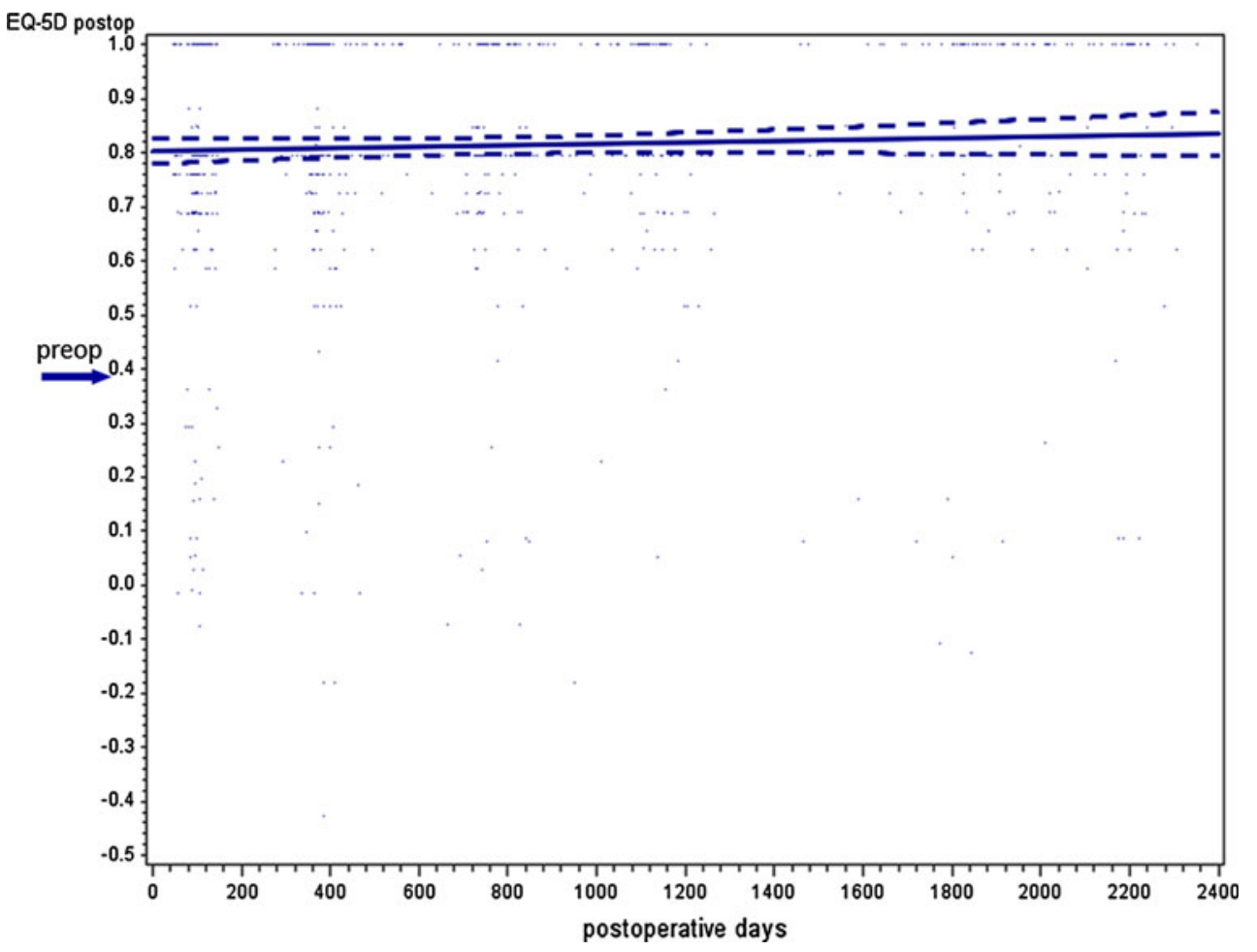

The independent assessment of functional X-ray measurements showed that in $11.8 \%$ of the segments range of motion (ROM) was between $0^{\circ}$ and $2^{\circ}$. The average range of motion of the remaining mobile segments $(88.2 \%)$ was $10.2^{\circ}$ (range $2^{\circ}-25^{\circ}, \mathrm{SD} 5.5^{\circ}$ ). In patients treated on two levels, the caudal segments were on average $4.4^{\circ}$ less mobile than the cranial $\left(8.2^{\circ}\right.$ vs. $\left.12.6^{\circ}, p=0.038\right)$. Regarding osteophytes, $10.2 \%$ of segments were classified as McAfee grade $0,49.1 \%$ as grade I, $25.9 \%$ as grade II, $13.9 \%$ as grade III and $0.9 \%$ as grade IV.
Complication and revision rates

During surgery a total of one blood vessel injury and one dura lesion occurred in two patients. The rate for intraoperative complications was hence $0.6 \%$. Postoperatively, in 22 patients $(7.2 \%)$ either a dysphonia $(n=13)$ or a dysphagia $(n=9)$ was diagnosed. Two further patients underwent an early revision surgery $(0.6 \%)$ : one implant removal and spondylodesis and another hematoma evacuation were performed. Another 12 patients (3.6 \%) underwent 
a different type of early re-intervention, which was not further specified.

During follow-ups 13 patients $(3.9 \%)$ reported a dysphagia $(n=12)$ or a dysphonia $(n=2)$. One patient had both dysphonia and dysphagia. In 11 of these 13 patients the complication was new $(11 / 332,3.3 \%)$. In all of these patients except one the symptoms disappeared until the 2-year follow-up. In one patient the dysphagia was persisting at his last available 3-year follow-up.

Over the course of the follow-up period 24 patients $(7.2 \%)$ reported on 28 other complications, directly or indirectly related to surgery (neck pain $n=10$; cervical radiculopathy on a new level $n=3$; fibromyalgia $n=3$; facet joint syndrome $n=2$; cervical distortion $n=2$; symptomatic stenosis on a new level $n=2$; depression $n=1$; headache $n=1$; subcutaneous pressure pain $n=1$; vertigo $n=1$; spontaneous fusion $n=1$ ).

During the five postoperative years 13 patients (3.9\%) needed to undergo a revision surgery after hospital discharge. Twelve patients were monosegmental $(4.4 \%)$ and one bisegmental $(1.7 \%)$ cases.

\section{Adjacent segment degeneration}

Thirty-seven patients (11.1\%) developed signs of ASD progression. Thirty-five out of 37 patients were treated on one segment (total of $12.8 \%$ for monosegmental patients) and two other patients on two segments (total of $3.4 \%$ for bisegmental patients). Thirty patients out of 37 (total of $9 \%$ ) had progression of cranial adjacent segment and 10 out of 37 patients (total of $3 \%$ ) had progression of caudal adjacent segment degeneration. Thus, in three patients both cranial and caudal segment degenerations were documented.

Eleven out of 37 patients and four other patients (in total $n=15 ; 4.6 \%$ ) also had a progression of degeneration of a distant segment. Progression of distant segment degeneration occurred in 14 patients with a monosegmental surgery (total of $5.1 \%$ of monosegmental patients) and in one patient with a bisegmental surgery (total of $1.7 \%$ of bisegmental patients). Seven out of 15 patients (total of $2.1 \%$ ) had progression of a distant segment degeneration cranially and nine (total of $2.7 \%$ ) caudally to the treated segment. Thus, in one patient progression of both a cranial and caudal distant segment were documented.

\section{Discussion}

The position of cervical total disc arthroplasty in the hierarchy of spinal surgical procedures is not yet completely clear, as the hypothesized theoretical advantages of the TDA in prevention of adjacent segment disease still need to be confirmed in long-term studies, ideally with a comparator. Short- and mid-term comparisons with the gold standard-cervical fusion-are promising. In a randomized study, Upadhyaya et al. [12] showed that arthroplasty had similarly excellent 2 years results as fusion, but associated with a lower rate of secondary surgery and a higher rate of neurological success. In 2011 Coric et al. [8] reported that Kineflex-C was associated with a significantly greater overall success rate than fusion while maintaining motion at the index level at 2 years after surgery. In his previous study from 2010 TDA prostheses (Bryan, Kineflex/C and Discover cervical discs) showed significantly better clinical results, maintained motion at the treated level, and tended toward less adjacent-level disease than fusion [13].

Well studied is the evidence of cervical TDA in the short- and mid-term perspective. Ren et al. [14] showed good intermediate clinical outcome with the Bryan disc at an average follow-up of 35 months. Good intermediate results in 40 patients with the Prestige LP were shown by Peng et al. [15] 2 years postoperative. However, the reports with follow-ups longer than 5 years are still rare. Goffin et al. [16] confirmed that the favorable clinical and functional early postoperative outcome after Bryan TDA persisted after 4-6 years. Recently, Quan et al. [17] published 8 -year results of 21 patients with Bryan discs and confirmed favorable clinical and radiological outcome in the majority of cases, also describing an increasing incidence of heterotopic ossifications over time.

Pain relief, medication consumption and quality of life

The results of the current study showed significant and stable neck and arm pain relief over the 5 postoperative years. Postoperative arm pain was on average 5-6 VAS points lower than neck pain. This improvement is reflected in significantly reduced medication consumption and increased quality of life. The reported short-term results of cervical TDA in SWISSspine by Schluessmann et al. are in accordance with our study. Slightly lower neck (21 vs. 24.8 in [9]), but very similar arm pain (17 vs. 17.6 in [9]) and EQ-5D score were seen at 2-year results and 5-year results in the registry.

Segmental mobility and ossification

$14.8 \%$ of segments had an advanced ossification affecting the segmental ROM (McAfee grades III and IV) [11]. Another $25.9 \%$ had an ossification potentially affecting the segmental ROM (McAfee grade II). Both combined make up $40.7 \%$ of segments. A recent meta-analysis on heterotopic ossification by Chen et al. [18] showed a pooled prevalence of $11.1 \%$ of advanced $\mathrm{HO}$ at the 12-month follow-up. This pooled prevalence increased to 
$16.7 \%$ at 24 months. The pooled prevalence of any ossification was $44.6 \%$ at 12 months and $58.2 \%$ at 24-month [18]. In our study, $89.2 \%$ of patients had an ossification $\geq$ grade $\mathrm{I}$ at the 5-year follow-up. Many publications, however, reported that $\mathrm{HO}$ was not affecting clinical improvement [6, 19-24]. The clinical relevance of the low grade ossifications is questionable. In the current analysis, around $90 \%$ of segments were mobile with an average range of motion of $10^{\circ}$ and stable postoperative neck pain relief over time. Walraevens followed up 76 patients with Bryan discs after 6 years and $87 \%$ of them had mobile devices; of the 26 cases with an 8-year follow-up $88 \%$ had mobile discs [25]. Other studies have reported segmental ROM to be ranging between $7.3^{\circ}$ and $10.6^{\circ}$ at follow-ups between the 2nd and 8th follow-up year [6, 16, 17, 25-27]. According to Kim et al. [26] the postoperative ROM of the treated segments seems to be well preserved compared with the preoperative one [25], or, as Wenger et al. [27] reported, in comparison to the ROM of the adjacent levels.

Surgeon assessments and the independent assessment of functional X-ray measurements were similar regarding segment mobility. According to those assessments, between 9.8 and $11.8 \%$ of the segments can be regarded as immobile.

\section{Complications and revisions}

A systematic review and meta-analysis of RCTs by $\mathrm{Yu}$ et al. [28] reported an overall reoperation rate of $2.8 \%$ for cervical TDA and $7.5 \%$ for anterior discectomy and fusion at 2-year follow-up, which was significantly different. Different prospective randomized single-level studies comparing cervical TDA to anterior discectomy and fusion reported variable revision rates between 1.8 and $11 \%$ $[8,13,29-31]$. Our rate for reoperation at 5.4 years followup was $3.9 \%$, which lies well in between the range of the rates seen in other studies.

The meta-analysis by Jiang et al. [32] showed a statistical difference favoring cervical TDA over anterior cervical discectomy and fusion regarding dysphagia incidence. Practically, in all our patients the symptoms of dysphagia and dysphonia disappeared until the 2-year follow-up, which points to a temporary character of these complications.

\section{Adjacent segment degeneration}

Preservation of motion in total disc arthroplasty is expected to decrease the risk for ASD in comparison with segmental fusion. A recent experimental study by Barrey et al. [33] showed that 1 and 2-level TDA generates better biomechanical conditions than arthrodesis at adjacent levels limiting contribution of these segments to global ROM and reducing the amount of their internal stresses. The current status of clinical evidence on this issue remains uncertain.
Goffin et al. [34] reported a $92 \%$ incidence of adjacentlevel degeneration after anterior discectomy and fusion. Similarly, Hilibrand et al. [35] reported a cumulative risk of $25 \%$ for adjacent segment degeneration at long-term follow-up after anterior discectomy and fusion. Recently, Nunley et al. [36] reported $14.3 \%$ of ASD after anterior discectomy and fusion and $16.8 \%$ after cervical TDA after approximately 3 years postoperative and concluded on an equivalent risk for both procedures. The recent metaanalysis of randomized controlled trials (RCT) comparing cervical TDA and anterior cervical discectomy and fusion by Yang et al. [37] showed an average $8.8 \%$ ASD rate after cervical TDA in comparison to $13 \%$ after fusion. This difference was, however, not significant and the authors encouraged more high-quality long-term and large sample size RCTs. In our relatively large patient sample with an average follow-up time of 5.4 years $11.1 \%$ of ASD and $4.6 \%$ of distant segment degeneration were documented. Our rate of ASD is not disagreeing with those observed in other studies. Interestingly, the cranial ASD rate was 3-fold higher than the caudal one. Another important observation was that the rate of distant segment degeneration was only half as high as the ASD rate.

\section{Difficulties in SWISSspine long-term follow-ups}

The execution of 5-year follow-up in this national registry was complex and related to several factors: (1) the national multi-centric multilingual character of the registry including 39 clinics and 54 surgeons in the 2005/06 time period, with whom close (ideally personal) contacts needed to be kept, (2) the need for communication with the treated patients via their surgeon and their secretary and not via the data collection center that initiated and led the follow-up project, (3) difficulties to motivate surgeons and their staff to identify and contact their patients, and to convince patients to present for follow-up despite good clinical outcomes, (4) out of pocket expenses for patients for radiography if a deductible is a part of the insurance contract, which is very common in Switzerland, (5) the long-term character of the study with additional problems in reaching patients and surgeons in case of change of address or place of work.

Limitations and strengths

The following limitations deserve mention. Being an observational unmonitored study a potential underreporting of surgeon-based outcomes like complication and revision rates cannot be completely excluded. All surgeons participating in the documentation are certified by the Swiss Spine Society for conducting cervical TDA surgery, which means that they have proven the essential training and qualifications and have agreed to accurately document the 
interventions. The accordance between the surgeon-based and independent measurements of ROM shows a rather conscientious documentation. An audit or any other control mechanism in a national registry would need strong financial and organizational resources and was considered as not feasible by the stakeholders of the project.

Furthermore, no direct treatment comparator is included in the SWISSspine documentation. A complete documentation of a gold standard procedure like fusion in a national registry would need additional and substantial administrative and financial efforts, which were considered even less feasible. A cost-effective solution to this weakness is, e.g., a cross-registry comparison that has recently been undertaken for lumbar TDA in the SWISSspine and anterior interbody fusion in the Spine Tango registry [38]. A within registry benchmarking is also possible as this has been shown for lumbar TDA in the SWISSspine registry [39].

On the other hand, the registry represents real-world and nationwide data including different treatment centers and implants. This is the first large series of 5-year follow-up of a data pool with different types of cervical discs.

\section{Conclusions}

Cervical TDA provides a significant, clinically relevant and stable neck and arm pain relief in the 5-year perspective. Consumption of analgesics is consequently significantly decreased and QoL improved to a considerable extent. The procedure appears sufficiently safe.

\footnotetext{
Acknowledgments The authors are thankful to the SWISSspine registry group who made this research possible by populating the database with their valuable and much appreciated entries. Among others, the data of following colleagues were used in the study: Bärlocher C $(n=45)$, Sgier F $(n=40)$, Hasdemir M $(n=21)$, Etter C $(n=14)$, Markwalder $\mathrm{T}(n=14)$, Favre $\mathrm{J}(n=12)$, Ramadan $\mathrm{A}(n=12)$, Wernli $\mathrm{F}(n=12)$, Maestretti $\mathrm{G}(n=10)$, Porchet $\mathrm{F}(n=10)$, Baur $\mathrm{M}(n=9)$, Cathrein $\mathrm{P}$ $(n=8)$, Hausmann $\mathrm{O}(n=8)$, Grob $\mathrm{D}(n=8)$, Otten $\mathrm{P}(n=8)$, Tessitore $\mathrm{E}(n=8)$, Heimberger $\mathrm{K}(n=7)$, Bothmann $\mathrm{M}(n=6)$, Ebeling $\mathrm{U}(n=5)$, Scheufler KM $(n=5)$, Uehlinger K $(n=5)$, Aebi M $(n=4)$, Boos $\mathrm{N}(n=4)$, Hamburger $\mathrm{C}(n=4)$, Kast $\mathrm{E}(n=4)$, Schaeren S $(n=4)$, Forster T $(n=3)$, Hora J $(n=3)$, Min $\mathrm{K}(n=3)$, Morard M $(n=3)$, Moulin P $(n=3)$, Stoll TM $(n=3)$, Steinsiepe F $(n=3)$, Berlemann $\mathrm{U}(n=2)$, Boscherini $\mathrm{D}(n=2)$, Heini $\mathrm{P}(n=2)$, Kraus U $(n=2)$, Marchesi D $(n=2)$, Martinez $\mathrm{R}(n=2)$, Oberle J $(n=2)$, Renella $\mathrm{R}(n=2)$, Schwarzenbach $\mathrm{O}(n=2)$, Bartanusz $\mathrm{V}$ $(n=1)$, Binggeli $\mathrm{R}(n=1)$, Bongioanni $\mathrm{F}(n=1)$, Jeanneret $\mathrm{B}(n=1)$, Kroeber $\mathrm{M}(n=1)$, Schianchi $\mathrm{P}(n=1)$. Funded by the AO Foundation start-up-grant S-10-41A.
}

Conflict of interest None.

\section{References}

1. Resnick DK, Watters WC (2007) Lumbar disc arthroplasty: a critical review. Clin Neurosurg 54:83-87
2. Singh K, Vaccaro AR, Albert TJ (2004) Assessing the potential impact of total disc arthroplasty on surgeon practice patterns in North America. Spine J 4:195S-201S. doi:10.1016/j.spinee.2004. 07.009

3. Richards O, Choi D, Timothy J (2012) Cervical arthroplasty: the beginning, the middle, the end? Br J Neurosurg 26:2-6. doi: 10(3109/02688697).2011.595846

4. Denaro V, Papalia R, Denaro L, Di Martino A, Maffulli N (2009) Cervical spinal disc replacement. J Bone Jt Surg Br 91:713-719. doi:10.1302/0301-620X.91B6.22025

5. Goffin J, Van Calenbergh F, van Loon J, Casey A, Kehr P, Liebig K, Lind B, Logroscino C, Sgrambiglia R, Pointillart V (2003) Intermediate follow-up after treatment of degenerative disc disease with the Bryan Cervical Disc Prosthesis: single-level and bilevel. Spine (Phila Pa 1976) 28:2673-2678. doi:10.1097/01. BRS.0000099392.90849.AA

6. Beaurain J, Bernard P, Dufour T, Fuentes JM, Hovorka I, Huppert J, Steib JP, Vital JM, Aubourg L, Vila T (2009) Intermediate clinical and radiological results of cervical TDR (Mobi-C) with up to 2 years of follow-up. Eur Spine J 18:841-850. doi: 10.1007/s00586-009-1017-6

7. Ahn PG, Kim KN, Moon SW, Kim KS (2009) Changes in cervical range of motion and sagittal alignment in early and late phases after total disc replacement: radiographic follow-up exceeding 2 years. J Neurosurg Spine 11:688-695. doi:10.3171/ 2009.7.SPINE0946

8. Coric D, Nunley PD, Guyer RD, Musante D, Carmody CN, Gordon CR, Lauryssen C, Ohnmeiss DD, Boltes MO (2011) Prospective, randomized, multicenter study of cervical arthroplasty: 269 patients from the Kineflex|C artificial disc investigational device exemption study with a minimum 2-year follow-up: clinical article. J Neurosurg Spine 15:348-358. doi:10.3171/ 2011.5.SPINE10769

9. Schluessmann E, Aghayev E, Staub L, Moulin P, Zweig T, Roder C, SWISSspine (2010) SWISSspine: The case of a governmentally required HTA-registry for total disc arthroplasty. Results of cervical disc prostheses. Spine (Phila Pa 1976) 35(24):E13971405

10. IEFO (2012) www.memdoc.org. University of Bern, Switzerland 11. McAfee PC, Cunningham BW, Devine J, Williams E, Yu-Yahiro J (2003) Classification of heterotopic ossification (HO) in artificial disk replacement. J Spinal Disord Tech 16:384-389

12. Upadhyaya CD, Wu JC, Trost G, Haid RW, Traynelis VC, Tay B, Coric D, Mummaneni PV (2012) Analysis of the three United States Food and Drug Administration investigational device exemption cervical arthroplasty trials. J Neurosurg Spine 16:216-228. doi:10.3171/2011.6.SPINE10623

13. Coric D, Cassis J, Carew JD, Boltes MO (2010) Prospective study of cervical arthroplasty in 98 patients involved in 1 of 3 separate investigational device exemption studies from a single investigational site with a minimum 2-year follow-up. Clin article. J Neurosurg Spine 13:715-721. doi:10.3171/2010.5.SPINE09852

14. Ren X, Wang W, Chu T, Wang J, Li C, Jiang T (2011) The intermediate clinical outcome and its limitations of Bryan cervical arthroplasty for treatment of cervical disc herniation. J Spinal Disord Tech 24:221-229. doi:10.1097/BSD.0b013e 3181e9f309

15. Peng CW, Yue WM, Basit A, Guo CM, Tow BP, Chen JL, Nidu M, Yeo W, Tan SB (2011) Intermediate results of the prestige LP cervical disc replacement: clinical and radiological analysis with minimum two-year follow-up. Spine (Phila Pa 1976) 36:E105E111. doi:10.1097/BRS.0b013e3181d76f99

16. Goffin J, van Loon J, Van Calenbergh F, Lipscomb B (2010) A clinical analysis of 4- and 6-year follow-up results after cervical disc replacement surgery using the Bryan cervical disc prosthesis. J Neurosurg Spine 12:261-269. doi:10.3171/2009.9.SPINE09129 
17. Quan GM, Vital JM, Hansen S, Pointillart V (2011) Eight-year clinical and radiological follow-up of the Bryan cervical disc arthroplasty. Spine (Phila Pa 1976) 36:639-646. doi:10.1097/ BRS.0b013e3181dc9b51

18. Chen J, Wang X, Bai W, Shen X, Yuan W (2012) Prevalence of heterotopic ossification after cervical total disc arthroplasty: a meta-analysis. Eur Spine J 21:674-680. doi:10.1007/s00586-0112094-x

19. Mehren C, Suchomel P, Grochulla F, Barsa P, Sourkova P, Hradil J, Korge A, Mayer HM (2006) Heterotopic ossification in total cervical artificial disc replacement. Spine (Phila Pa 1976) 31:2802-2806. doi:10.1097/01.brs.0000245852.70594.d5

20. Leung C, Casey AT, Goffin J, Kehr P, Liebig K, Lind B, Logroscino C, Pointillart V (2005) Clinical significance of heterotopic ossification in cervical disc replacement: a prospective multicenter clinical trial. Neurosurgery 57:759-763 (Discussion 759-763)

21. Lee JH, Jung TG, Kim HS, Jang JS, Lee SH (2010) Analysis of the incidence and clinical effect of the heterotopic ossification in a single-level cervical artificial disc replacement. Spine J 10:676-682. doi:10.1016/j.spinee.2010.04.017

22. Yi S, Kim KN, Yang MS, Yang JW, Kim H, Ha Y, do Yoon H, Shin HC (2010) Difference in occurrence of heterotopic ossification according to prosthesis type in the cervical artificial disc replacement. Spine (Phila Pa 1976) 35:1556-1561. doi:10.1097/ BRS.0b013e3181c6526b

23. Suchomel P, Jurak L, Benes V 3rd, Brabec R, Bradac O, Elgawhary S (2010) Clinical results and development of heterotopic ossification in total cervical disc replacement during a 4-year follow-up. Eur Spine J 19:307-315. doi:10.1007/s00586009-1259-3

24. Heidecke V, Burkert W, Brucke M, Rainov NG (2008) Intervertebral disc replacement for cervical degenerative disease — clinical results and functional outcome at two years in patients implanted with the Bryan cervical disc prosthesis. Acta neurochirurgica 150:453-459. doi:10.1007/s00701-008-1552-7 (Discussion 459)

25. Walraevens J, Demaerel P, Suetens P, Van Calenbergh F, van Loon J, Vander Sloten J, Goffin J (2010) Longitudinal prospective long-term radiographic follow-up after treatment of singlelevel cervical disk disease with the Bryan cervical disc. Neurosurgery 67:679-687. doi:10.1227/01.NEU.0000377039.89725.F3 (Discussion 687)

26. Kim HK, Kim MH, Cho DS, Kim SH (2009) Surgical outcome of cervical arthroplasty using bryan(r). J Korean Neurosurg Soc 46:532-537. doi:10.3340/jkns.2009.46.6.532

27. Wenger M, Hoonacker P, Zachee B, Lange R, Markwalder TM (2009) Bryan cervical disc prostheses: preservation of function over time. J Clin Neurosci 16:220-225. doi:10.1016/j.jocn.2008. 01.021

28. Yu L, Song Y, Yang X, Lv C (2011) Systematic review and metaanalysis of randomized controlled trials: comparison of total disk replacement with anterior cervical decompression and fusion. Orthopedics 34:e651-e658. doi:10.3928/01477447-20110826-09
29. Mummaneni PV, Robinson JC, Haid RW Jr (2007) Cervical arthroplasty with the Prestige LP cervical disc. Neurosurgery 60:310-314. doi:10.1227/01.NEU.0000255376.42099.13 (Discussion 314-315)

30. Murrey D, Janssen M, Delamarter R, Goldstein J, Zigler J, Tay B, Darden B (2009) Results of the prospective, randomized, controlled multicenter Food and Drug Administration investigational device exemption study of the ProDisc-C total disc replacement versus anterior discectomy and fusion for the treatment of 1-level symptomatic cervical disc disease. Spine J 9:275-286. doi: 10.1016/j.spinee.2008.05.006

31. Anderson PA, Sasso RC, Riew KD (2008) Comparison of adverse events between the Bryan artificial cervical disc and anterior cervical arthrodesis. Spine (Phila Pa 1976) 33:1305-1312. doi: 10.1097/BRS.0b013e31817329a1

32. Jiang H, Zhu Z, Qiu Y, Qian B, Qiu X, Ji M (2012) Cervical disc arthroplasty versus fusion for single-level symptomatic cervical disc disease: a meta-analysis of randomized controlled trials. Arch Orthop Trauma Surg 132:141-151. doi:10.1007/s00402011-1401-7

33. Barrey C, Campana S, Persohn S, Perrin G, Skalli W (2012) Cervical disc prosthesis versus arthrodesis using one-level, hybrid and two-level constructs: an in vitro investigation. Eur Spine J 21:432-442. doi:10.1007/s00586-011-1974-4

34. Goffin J, Geusens E, Vantomme N, Quintens E, Waerzeggers Y, Depreitere B, Van Calenbergh F, van Loon J (2004) Long-term follow-up after interbody fusion of the cervical spine. J Spinal Disord Tech 17:79-85

35. Hilibrand AS, Carlson GD, Palumbo MA, Jones PK, Bohlman HH (1999) Radiculopathy and myelopathy at segments adjacent to the site of a previous anterior cervical arthrodesis. $\mathrm{J}$ Bone $\mathrm{Jt}$ Surg Am 81:519-528

36. Nunley PD, Jawahar A, Kerr EJ 3rd, Gordon CJ, Cavanaugh DA, Birdsong EM, Stocks M, Danielson G (2012) Factors affecting the incidence of symptomatic adjacent-level disease in cervical spine after total disc arthroplasty: 2- to 4-year follow-up of 3 prospective randomized trials. Spine (Phila Pa 1976) 37:445-451. doi:10.1097/BRS.0b013e31822174b3

37. Yang B, Li H, Zhang T, He X, Xu S (2012) The incidence of adjacent segment degeneration after cervical disc arthroplasty (CDA): a meta analysis of randomized controlled trials. PLoS One 7:e35032. doi:10.1371/journal.pone.0035032

38. Aghayev E, Henning J, Munting E, Diel P, Moulin P, Roder C, Swissspine, Spine Tango Registry groups (2012) Comparative effectiveness research across two spine registries. Eur Spine J 21:1640-1647. doi:10.1007/s00586-012-2256-5

39. Aghayev E, Roder C, Zweig T, Etter C, Schwarzenbach O (2010) Benchmarking in the SWISSspine Registry: results of 52 dynardi lumbar total disc replacements compared with the data pool of 431 other lumbar disc prostheses. Eur Spine J 19(12):2190-2199. doi:10.1007/s00586-010-1550-3 